\title{
Levels of Loneliness and Family Structure among Geriatrics
}

Ayla $\mathbf{K}^{1}$ and Kanwal $\mathbf{S}^{2^{*}}$

${ }^{1}$ Centre for Counseling and Career Advisory, National University of Sciences and Technology, Islamabad, Pakistan

${ }^{2}$ Psychology \& Education Department, Foundation University Rawalpindi Campus, Foundation University Islamabad, Islamabad, Pakistan

*Corresponding author: Kanwal Shahbaz, Psychology \& Education Department, Foundation University Rawalpindi Campus, Foundation University Islamabad, Pakistan, Tel: +923348387824; E-mail: Psykanwal@gmail.com

Received date: February 19, 2018, Accepted date: March 05, 2018, Published date: March 09, 2018

Copyright: $\odot 2018$ Ayla K, et al. This is an open-access article distributed under the terms of the Creative Commons Attribution License, which permits unrestricted use, distribution, and reproduction in any medium, provided the original author and source are credited.

\begin{abstract}
Loneliness is a pressing social issue for geriatrics globally. The purpose of present study is to explore the effect of family structure on level of loneliness in geriatrics. For this purpose, researcher formulated the three hypotheses: 1) Geriatric adults residing within the joint family system feel less loneliness as compare to those residing in nuclear family system 2) Nuclear family system predicts more loneliness in elderly people contrary to joint family system 3 ) There is likely more loneliness in females in both family systems rather than males. Cross-sectional quantitative study was conducted by using the stratified random probability sampling technique. Data were collected from $(\mathrm{N}=246)$ geriatrics living in nuclear and joint families of district Haripur. Researcher measured the loneliness by using the translated version of UCLA Loneliness Scale (Version 3). The data was analyzed by using the SPSS XXIII. Study findings supported the hypothesis and it was concluded that geriatric adults residing within the joint family system feel less loneliness level as compare to those living in nuclear family system. Further, it highlights that the role of nuclear family system is higher in increasing the level of loneliness and level of loneliness is high in females as compare to males. Research findings have great implications for improving the conditions of older adults in nuclear family structure.
\end{abstract}

Keywords: Loneliness; Family structure; Geriatrics

\section{Introduction}

In today's world of work, elders are facing problems such as depression, feeling of neglect, loneliness and isolation. Due to rapid increase in nuclear families and global trend of employment opportunities, elders are compelled to live alone. Rook mentioned loneliness is an emotional state that arose when an individual feels rejected by others and lacks partners for social activities [1,2]. There is possibility of occurring loneliness in all age groups but this problem is mostly relevant to elders. There is direct relationship between age and loneliness [3]. Loneliness is an emotional state in which an individual suffers from the inner emptiness and social isolation [4].

Previous literature has shown that there are certain features that are present in lonely peoples such as having history of loss, misery and lack of support systems. Loneliness causes expressions of annoyance, grief, dimness, pettiness, unpleasantness, vanity, vulnerability and sarcasm in elders. There is lack of self-motivation and empathy in lonely people due to which they remain isolated and mostly stay away from others. Storr mentioned that lonely people have fear of rejection due to which they keep themselves off from others [5].

There are different reasons due to which loneliness occurs in geriatric adults. Changes in societal and personal relations particularly loss of beloved one, migration from one place to another, divorce or break up etc., cause loneliness [6]. Dykstr et al. indicated that decrease in interaction and communication with family members and peer fellows encourage loneliness in elder adults [7]. Multiple factors such as demographic variables, living measures, public support and personality features are also involved in causing the loneliness state [8].
According to World Health organization there is no fixed criteria but usually above 60+ years fall in older adults' category [9]. Aging is time taken process and it affects an individual's complete body shape and increase vulnerability to main chronic diseases [10]. It is often seemed as difficult phase of one's life and it is also true to some extent. In this age, elders are dependent upon others, their social activities become reduced and as a result elders' life becomes vulnerable [11]. In this case, family play major role in providing care to human body. Family is consisted of married couples and group of adults who collaborate with each other in the upbringing of children.

Though family structure varies with time across cultures from 60 years and it has six primary tasks reproduction, shelter and socialization, regulation of sexual behavior, love, friendship and provision of social status [12]. When family changes its structure to fit in society due to urbanization, than automatically its function change. Due to emergence of modernism, joint family has been replaced by nuclear family. Nuclear family is the typical family that is based upon parents and their biological offspring's [13]. While joint family system (JFS) includes two or more nuclear families that form a corporate financial unit [14]. Family is a place where individuals feel comfort, security and help when needed. Elders are the most happy and comfortable with their family and children [15]. WHO declared that on the basis of research across the culture that elder adult select to live with their families and communities [16].

Diversity exists between the eastern and western culture which contributes and effects in the study phenomena. Le Roux mentioned that cultural variation does exists and effect the loneliness experience [17]. There is stronger desire to live with family among collectivists culture as compare to individualistic culture [18]. Pinquart examined loneliness in German older adults and found that frequent contact with family friends, youngster, friends and siblings play major role in 
decreasing the level of loneliness [19]. Comparative study was done on loneliness in Eastern Europe which revealed that Eastern Bloc countries of Russia, Bulgaria \& Georgia, relative to France \& Germany possessed significantly higher level of loneliness [7]. Iecovich et al. examined that susceptibility to loneliness was associated with weak social networks [20].

Proportion of elders' population increases and Asia is the one of the region where majority of world's population exists. Modernization also brings changes in eastern culture [21]. Tsai et al. found out that $25 \%$ elders' families are alone in China while $35 \%$ are suffering from loneliness [22]. Due to loneliness other psychological and psychosocial problems also aroused in elder adults. Pakistani culture is rich in their social, ethical and religious values but with the passage of time values are changing abruptly and family integration is one of the major victim of this change [23].

\section{Methods}

\section{Objectives}

Objectives of the study are given below

- To study the loneliness level in both family systems at geriatric stage.

- To compare both family system environment effect on loneliness level in geriatric.

- To investigate the influence of gender difference on loneliness level in elderly people in both family systems.

\section{Hypothesis}

- H1: Geriatric adults residing within the joint family system feel less loneliness as compare to those residing in nuclear family system.

- H2: Nuclear family system predicts more loneliness in elderly people contrary to joint family system.

- H3: There is likely more loneliness in females than males in both types of family systems

\section{Variables of the study}

\section{Loneliness}

Loneliness is the condition of emotional distress along feeling one's deficiencies in social relationship [6]. It is operationalized as the scoring of UCLA Loneliness scale version 3. High scoring means high level of loneliness.

\section{Nuclear family}

It is comprised of small unit having married couple with their children [24]. Scores of UCLA loneliness scale version 3 determine the level of loneliness in nuclear families.

\section{Joint family}

It include more than two or more nuclear family units that are providing more social support and consists of parents and their children [25]. Scores of UCLA loneliness scale version 3 determine the level of loneliness in joint families.

\section{Instruments of the study}

Urdu translated version of UCLA Loneliness Scale (3) is used to measure the level of loneliness in adults. UCLA loneliness scale was translated and it consists of 20 items and respondents rate each item as O (I often feel this way), S (I sometimes feel this way), R (I rarely feel this way) and $\mathrm{N}$ (I never feel this way). An item is worded to suggest a general, present-day experience that relates to both social and emotional dimensions of loneliness (e.g. I feel a part of a group of friends, No one really knows me well). The wording of the items and response format has been simplified to facilitate administration of the measure to less educated populations such as the elderly. Higher scores on this scale indicate more intense feelings of loneliness. Alpha reliability of this scale is 0.990 [1].

\section{Research design}

The present study is based on quantitative analysis and survey technique is used to determine the level of loneliness in nuclear and joint family system.

\section{Sample and population}

The target population of present study consisted of aged people living in the nuclear and joint setup of Haripur District. The sample of present study consisted of 246 participants which are selected through applying stratified random probability sampling technique. Age of participants in this study is above 50 and data is collected from both male and female participants.

\section{Procedure}

For data collection, researcher personally visited the nuclear and joint family system for collecting the responses from adults. Participants were told about the purpose of study and their willingness to participate in study was taken. They were ensured that their data should be kept confidential and used for research purpose only. After collecting the data, results were analyzed by using the SPSS software.

\section{Results}

Different statistical techniques are applied for data analysis in order to meet the objectives of present study. Alpha reliability and inter item correlation is used to determine the psychometric properties of scales. Level of loneliness in family systems and on gender basis is determined through $\mathrm{t}$-analysis. Results are shown in the form of tables given below:

\section{Reliability of UCLA loneliness scale items}

\begin{tabular}{|l|l|l|}
\hline Variable & N & $\alpha$ \\
\hline Loneliness & 246 & 0.9 \\
\hline Note: N=Item no, $\alpha=$ Alpha coefficient \\
\hline
\end{tabular}

Table 1: Alpha reliability coefficients of UCLA loneliness scale items for $\mathrm{N}(20)$.

In order to explore the internal consistency of instrument (UCLA Loneliness scale), their alpha reliability coefficients is computed as mentioned in Table 1. The alpha coefficient for UCLA Loneliness scale 20 items is 0.906 which indicates that the scale items consistently measuring the acquired subject matter loneliness. Consequently these 
Citation: Ayla K, Kanwal S (2018) Levels of Loneliness and Family Structure among Geriatrics. J Foren Psy 3: 135. doi:10.4172/2475-319X. 1000135

Page 3 of 5

are highly reliable for measuring the loneliness. This value also matches with the Urdu version of UCLA and English version of UCLA scale that is 0.99 and 0.91 respectively. Result indicates this is the highly reliable tool for measuring the phenomenon under study.

\section{Correlation coefficient moment of UCLA loneliness scale items}

\begin{tabular}{|c|c|}
\hline $\mathrm{N}$ & $r$ (Loneliness) \\
\hline 1 & $0.463^{* *}$ \\
\hline 2 & $0.621^{* *}$ \\
\hline 3 & $0.440^{* *}$ \\
\hline 4 & $0.564^{* *}$ \\
\hline 5 & $0.678^{* *}$ \\
\hline 6 & $0.435^{* *}$ \\
\hline 7 & $0.627^{\star *}$ \\
\hline 8 & $0.612^{* *}$ \\
\hline 9 & $0.537^{* \star}$ \\
\hline 10 & $0.716^{* *}$ \\
\hline 11 & $0.715^{* *}$ \\
\hline 12 & $0.707^{* *}$ \\
\hline 13 & $0.599^{* *}$ \\
\hline 14 & $0.475^{* *}$ \\
\hline 15 & $0.630^{* *}$ \\
\hline 16 & $0.598^{* *}$ \\
\hline 17 & $0.550^{* *}$ \\
\hline 18 & $0.665^{* *}$ \\
\hline 19 & $0.760^{* *}$ \\
\hline 20 & $0.576^{* *}$ \\
\hline
\end{tabular}

${ }^{* *} p<0.01$

Table 2: Correlation coefficient moment of UCLA loneliness scale items.

In order to determine the construct validity of UCLA Loneliness scale, its item total correlation is computed as shown in Table 2. UCLA loneliness items highly co related with each other which indicates valid construct, measuring the same construct under study. Consequently this construct is reliable and valid.

Levels of loneliness in two different family systems

\begin{tabular}{|c|c|c|c|c|c|c|c|c|c|}
\hline \multirow[b]{3}{*}{$\begin{array}{l}\text { Variabl } \\
\text { e }\end{array}$} & \multicolumn{9}{|c|}{$\begin{array}{l}\text { Family System } \\
95 \% \text { C.I }\end{array}$} \\
\hline & \multicolumn{2}{|c|}{ Nuclear } & \multicolumn{2}{|l|}{ Joint } & \multirow{2}{*}{$\begin{array}{l}\mathrm{t}(244) \\
-\end{array}$} & \multirow[b]{2}{*}{$\mathrm{p}$} & \multirow[b]{2}{*}{ LL } & \multirow[b]{2}{*}{ UL } & \multirow{2}{*}{$\begin{array}{l}\text { Cohen's d } \\
\text { - }\end{array}$} \\
\hline & M & SD & M & SD & & & & & \\
\hline LoL & 38.1 & 12 & 24.7 & 9.8 & 9.21 & 0.002 & 10.4 & 16.15 & 1.17 \\
\hline \multicolumn{10}{|c|}{ " $p<0.005, L L=$ Level of Loneliness } \\
\hline \multicolumn{10}{|c|}{$\mathrm{M}=$ Mean; SD=Standard Deviation } \\
\hline
\end{tabular}

Table 3: Mean, standard deviation and t-values of nuclear and joint family systems on UCLA $(\mathrm{N}=246)$.

In order to investigate the loneliness level in varying family systems (nuclear and joint) descriptive statistics and t-values are computed.

The findings of Table 3 portray significant difference in level of loneliness in both family systems. It means that loneliness level is higher in nuclear family system as compare to joint family system. Mean value of loneliness level $(\mathrm{M}=38.10)$ is greater in nuclear family system as compare to joint family system that is $(M=24.79)$. Nuclear family system $(\mathrm{SD}=12.602)$ is for level of loneliness, Joint family system $(\mathrm{SD}=9.898)$ this indicates level of loneliness is higher in nuclear family system.

There is $p<0.005$ consequently in the present study significant difference exists between both family structures in degree of loneliness.

\section{Gender wise level of loneliness}

\begin{tabular}{|c|c|c|c|c|c|c|c|c|c|}
\hline \multirow[b]{3}{*}{ Variable } & \multicolumn{8}{|c|}{$\begin{array}{l}\text { Gender } \\
95 \% \text { C.I }\end{array}$} & \multirow{3}{*}{$\begin{array}{l}\text { Cohen's d } \\
- \\
-\end{array}$} \\
\hline & \multicolumn{2}{|l|}{ Male } & \multicolumn{2}{|c|}{ Female } & \multirow{2}{*}{$\begin{array}{l}\mathrm{t}(244) \\
-\end{array}$} & \multirow{2}{*}{$\begin{array}{l}\mathrm{p} \\
-\end{array}$} & \multirow{2}{*}{$\begin{array}{l}\mathrm{LL} \\
-\end{array}$} & \multirow{2}{*}{$\begin{array}{c}\text { UL } \\
-\end{array}$} & \\
\hline & M & SD & $\mathrm{M}$ & $\mathrm{SD}$ & & & & & \\
\hline LoL & 27.9 & 11.1 & 35 & 14 & 4.4 & 0.004 & 10.2 & 3.9 & 0.56 \\
\hline
\end{tabular}

Table 4: Mean, standard deviation and t-values of male and female elder adults on UCLA Scale $(\mathrm{N}=246)$.

In order to look at the loneliness level in gender (male and female) descriptive statistics and t-values are computed. The findings of Table 4 describe noteworthy difference in gender on the basis of loneliness level. It means that loneliness level is higher in female as compare to male in both family systems. Mean and Standard deviation value of loneliness level are 35.00 and 14.031 in female showing higher values as compare to male 27.89 and 11.122 in both family systems. Result is significant as $\mathrm{p}<0.005$. 
Item wise loneliness level in both family systems

\begin{tabular}{|c|c|c|c|c|c|c|}
\hline & \multicolumn{6}{|c|}{ Family Systems } \\
\hline & \multicolumn{2}{|c|}{ Nuclear $(\mathrm{N}=123)$} & \multicolumn{2}{|c|}{ Joint (N-123) } & \multirow[b]{2}{*}{$\mathrm{t}$} & \multirow[b]{2}{*}{$\mathrm{p}$} \\
\hline & M & SD & $M$ & SD & & \\
\hline Score 1 & 2.36 & 0.976 & 1.86 & 1.16 & $3.65^{*}$ & \\
\hline Score 2 & 1.97 & 0.896 & 1.24 & 1.04 & $5.84^{*}$ & 0 \\
\hline Score 3 & 2.08 & 0.997 & 1.85 & 1.1 & $1.60^{*}$ & 0.037 \\
\hline Score 4 & 1.75 & 0.98 & 1.24 & 1.08 & $3.86^{*}$ & 0 \\
\hline Score 5 & 2.02 & 0.992 & 1.42 & 1.01 & $4.66^{*}$ & 0 \\
\hline Score 6 & 1.82 & 0.975 & 1.46 & 1.11 & $2.64^{*}$ & 0.007 \\
\hline Score 7 & 1.7 & 1.15 & 1.16 & 1.09 & $3.70^{*}$ & 0 \\
\hline Score 8 & 1.84 & 1.07 & 1.07 & 0.99 & $5.74^{*}$ & 0 \\
\hline Score 9 & 1.98 & 0.976 & 1.3 & 1.05 & $4.72^{*}$ & 0 \\
\hline Score 10 & 1.98 & 1 & 1.19 & 11.05 & $5.54^{*}$ & 0 \\
\hline Score 11 & 1.93 & 1.2 & 0.9 & 0.98 & $6.56^{*}$ & 0 \\
\hline Score 12 & 1.35 & 1.03 & 1.02 & 1.051 & $6.80^{*}$ & 0 \\
\hline Score 13 & 1.93 & 1.2 & 0.9 & 0.9 & 0.986 & $6.56^{*}$ \\
\hline Score 14 & 1.9 & 1.03 & 1.02 & 1.02 & 1.051 & $6.80^{*}$ \\
\hline Score 16 & 1.73 & 1.03 & 1.01 & 1.01 & 0.94 & $5.76^{*}$ \\
\hline Score 17 & 2.39 & 0.86 & 1.66 & 1.66 & 1.149 & $5.67^{*}$ \\
\hline Score 18 & 2.04 & 1.04 & 1.13 & 1.13 & 1.007 & $7.02^{*}$ \\
\hline Score 19 & 1.81 & 1.07 & 0.99 & 0.99 & 0.972 & $6.26^{*}$ \\
\hline Score 20 & 1.81 & 1.03 & 1.17 & 1.17 & 1.05 & $4.76^{*}$ \\
\hline
\end{tabular}

Table 5: Difference in level of loneliness in two different family systems items wise.

In order to find the relationship between item scores and family system, descriptive statistics and t-values are computed. The Table 5 illustrate striking difference in level of loneliness in different scores of the loneliness scale. Results reveal that all items of the construct shows the significant difference in level of loneliness in both family systems because all items mean is higher in single family system and mean values low in joint family system, along with its $\mathrm{p}<0.005$ which indicates the significant difference in level of loneliness in both two different family systems.

\section{Discussions}

The present study investigated the effect of family structure on level of loneliness in geriatric. The findings of the study explained that loneliness level is higher in nuclear family as compared to joint system of family. There is significant difference in level of loneliness' gender wise females is more alone in nuclear family system irrespectively to males. Highly influencing age group to loneliness in nuclear family system is early geriatric.
First hypothesis of present research states that geriatric adults residing within the joint family system feel less loneliness as compare to those residing in nuclear family system. Findings shows there is significant difference lies between the loneliness level which is obtained by geriatric adults residing within joint families and nuclear family structure. Elders living in nuclear family systems report more loneliness as compare to those living in joint family system. Mason findings also approved this study phenomenon that joint family system provides more social support to adults of geriatric rather than nuclear family system. When elders receive more social support from their children then they feel lower level of loneliness. Elders living in joint family system receive more attention, care and social support from their children as compare to living alone [26].

Second hypothesis relate that nuclear family system predicts more loneliness in elderly people contrary to joint family system. Research finding shows there is significant difference in the level of loneliness in both different family systems. In joint family system collectively all members of the family take care of elderly people then, they feel less alone as compare to nuclear family system. One previous study of Ramamurti also approved this present study subject matter; investigations are on factors related to adjustment of urban aged in Madras City [27]. With regard to family type and marital status, results indicated that the individuals living in joint families were found to be significantly better adjusted than the individuals living in nuclear families. Research also found that the individuals in joint families had a higher role activity than those in the nuclear families. When elders were satisfied and give proper respect then automatically loneliness level will be low in joint family system.

Third hypothesis of the current study was that there is likely more loneliness in females in both these family systems rather than males. The results indicate that female possess higher level of loneliness as compare to males. This finding is in consistent with which loneliness level is higher in women as compare to men [28]. Furthermore, According to Hojat, women possess lower level of self-esteem which gives the association between loneliness and low self-esteem means they are more prone to loneliness [29-31]. The findings of the significant difference in loneliness in terms of gender may be caused by the characteristics of the participants more probably their gender role in the society. Probably, it can be stated that the social support networks are likely to be stronger for male as compare to females. Females mostly stay at home while males spent their time outside the home.

\section{Conclusions}

In conclusion study has gained the perspective that family structure affects the level of loneliness at geriatric. Findings reveal that geriatric adults residing within the joint family system feel less loneliness as compare to those residing in nuclear family system. Elderly people residencies within nuclear family system predict higher level of loneliness as compare to joint family system. Similarly nuclear family system predicts more loneliness in elderly people contrary to joint family system. And there is likely more loneliness in females in both these family system rather than males. Joint family system has a negative relationship between loneliness of both sexes.

\section{Recommendations}

Findings of the current study draw attention to many principal factors which significantly contributing in increasing the level of 
loneliness in nuclear family system. Consequently, there are some recommendations suggested by researcher to decrease the level of loneliness.

- Sharing and caring in nuclear family system with elderly people can overcome the level of loneliness. When in nuclear family system not neglect them and gave significance as valuable member of the family with love and affection, then we can overcome this problem in our society. Local peoples and well fare associations lunch there social support programs for elderly people for their psychological well-being.

- Engagement of them in different activities can reduce their level of loneliness. Policy makers pay attention for old care houses and shelters. Awareness should be provided to senior citizens with the help of media. For alleviating the loneliness, initiative such as visiting and befriending services should be taken. Try to engage elders' people in group activities so that they can remain active. When we increase their communication in society then we can reduce the level of loneliness in study population. Family members try to spent time with their elders and encourage them by sharing the meals.

\section{References}

1. Gul N (2015) Translation and adaptation the loneliness scale university of California angles. Sci Int 27: 731-732.

2. Rook KS (1984) Research on social support, loneliness and social isolation towards an

3. Integrated review of personality. J Soc Psychol 5: 239-264.

4. Barretta D, Dantzler D, Kayson W (1995). Factors related to loneliness. Psychol Rep 76: 827-830.

5. Murphy PM, Kupshik GA (1992) Loneliness, stress and well-being: A helper's guide. London, UK.

6. Storr A (1988) Solitude: A Return to the self. New York, USA.

7. Peplau LA, Perlman D (1982) Loneliness: A sourcebook of current theory, research and therapy. NewYork, USA.

8. Gierveld J (2008) Intergenerational relationships and transfers between older adults and their co-resident and non-co-resident children. European Population Conference, Barcelona, Spain.

9. Alpass FM, Neville S (2003) Loneliness and depression in older males. Aging Ment Health 7: 212-216.

10. World Health Organization (2014) Health Statistics and Information Systems.

11. Vijg J (2007) Aging of the Genome; The dual role of DNA in life and death. Oxford University Press, USA.

12. Neuhaus RH (1982) Successful Aging. John Willey and Sons; New York, USA.
13. Ogburn WF, Tibbits C (1933) The family and its functions, in president's research committee on social trends, recent social trends. McGraw Hill Book Co, New York, USA.

14. Parsons T, Bales RF (1955) Family, socialization and interaction process. The Free Press, New York, USA.

15. Levinson D, Malone MJ, Brown CH (1980) Toward explaining human culture: A critical review of the findings of worldwide cross-cultural research. HRAF Press, USA.

16. Läidmäe V, Tammsaar K, Tulva T, Kasepalu (2012) Quality of life of elderly in Estonia. Geriatr Gerontol Int 7: 1.

17. World Health Organization (2011) Global Health and Ageing.

18. Le Roux A (2009) The Relationship between adolescents' attitudes toward their fathers and loneliness, A cross-cultural study. J Child Fam Stud 18: 217-226.

19. Triandis HC (1989) The self and social behaviour in different cultural contexts. Psychol Rev 96: 269-89.

20. Pinquart M (2003) Loneliness in married, widowed, divorced and nevermarried older adult. J Soc Pers Relat 20: 31-53.

21. Iecovich E, Miriam B, Mirsky J, Kaufman R, Avgar A, et al. (2004) Social support networks and loneliness among elderly jews in Russia and Ukraine. J Marriage Fam 66: 306-317.

22. Chang TP (1992) Implication of changing family structure on geriatric support in the ESCAP Region. Asia Pac Popul J 7: 49-66.

23. Feng-Jen T, Eva T, Chang-Chuan C, Hiko T, Sandrine M, et al. (2013) Is the reporting timeliness gap for avian flu and H1N1 outbreaks in global health surveillance systems associated with country transparency? Globalization and Health. 9:14

24. Khan MA, Bhatti MA, Shahzadi AI (2011) Presentation of Pakistani cultural values about dressing in advertisements of local Urdu and English magazines: A comparative study of Akhbare-Jahan and Mag the weekly. Eur J Sci Res 51: 406-414.

25. Newman DM (2009) Families: A Sociological Perspective. Mc Graw-Hill, New York, USA.

26. Berkman LF, Glass T (2000) Social integration, social networks, social support, and health. In L. F. Berkman (edn), Social Epidemiology. Oxford Press, New York, USA.

27. Mason KO (1992) Family change and support of the elderly in Asia: What do we know? Asia Pac Popul J 7: 13-32.

28. Ramamurti PV (1972) A study of role availability, role utilization and problems of adjustment of middle aged and older people, Project report submitted to ICSSR. New Delhi, India.

29. Weiss RS (1973) Loneliness: The experience of emotional and social isolation. MIT Press, Cambridge, UK.

30. Hojat M (1982) Loneliness as a function of selected personality variables. J Clin Psychol 38: 137-141.

31. Chalise H (2010) Social support and its co-relation with loneliness: A cross-cultural study of Nepalese older adults. Int J Aging Hum Dev 71: 115-138. 